\title{
DETERMINATION OF PULSATION FACTORS OF THE SYSTEM OF SUPPRESSION OF INTERFERING HARMONICS OF A SEMICONDUCTOR CONVERTER
}

Purpose. The purpose of the paper is to define the pulsation factors of a closed-loop automatic control system (ACS) of
interfering harmonics containing a semiconductor converter with double-sided pulse-width modulation (PWM), as well as
confirmation of theoretical assumptions about possibilities of self-compensation of pulsation factors influence in the system
with double-sided PWM. Methodology. The research was conducted with the usage of classic electric circuit theory, frequency
analysis methods, generalized function theory. Results. The obtained expressions mathematically relate pulsation factors,
value of the damping coefficient and manipulative variable for different frequencies of interfering harmonics in the system
with double-sided PWM. The research concerned harmonics with frequencies $100,300,600,900$ and 1200 Hz as the most
significant constituents of the output voltage of a 12 -pulse semiconductor converter. The obtained expressions allow taking
into account settings of the selective link and its approximation on the level of supreme frequencies with aperiodic link.
Originality. The research has experimentally proved theoretical assumptions about self-compensation of pulsation factors in
the system with double-sided PWM. It has been shown that the damping coefficient has a low-impact influence on the values
of pulsation factors. It is caused by the pass band of the selective link, which is included in the closed-loop control system of
harmonics regulation. Practical value. Application of the research results can contribute to the development of the closed-loop
control system for effective attenuation of interfering harmonics in direct current contact wire without interfering in the
power part of the semiconductor converter. Besides the possibility to regulate output voltage, it will also help to solve the
problem of electromagnetic compatibility of a traction substation semiconductor converter with contact wire. The application
of the developed closed-loop control system will as well provide for decreasing the size of the filter in the direct current
traction substation unit. References 9 , figures 5 . Key words: pulsation factor, interfering semiconductor converter.

Цель. Целью статьи является определение факторов пульсаций замкнутой системы автоматического регулирования (САР) мешающих гармоник, содерэсащей полупроводниковый преобразователь с двухсторонней широтно-импульсной модуляцией (ШИМ), а также подтверждение теоретических предпосылок о возможсности самокомпенсации действия факторов пульсаций в системе с двухсторонней ШИМ. Методика. Для проведения работы использовались: классическая теория электрических цепей, методы гармонического анализа и теория обобщенных функций. Результаты. Получены выражения, математически связывающие факторы пульсаций, значения коэффициентов демпфирования и регулируемого параметра для разных частот мешающих гармоник в системе с двухсторонней ШИМ. Научная новизна. Экспериментально подтверждены теоретические предпосылки о самокомпенсации действия факторов пульсаций в системе с двухсторонней ШИМ; Практическое значение. Использование результатов работы позволит создать замкнутую САР для эффективного подавления мешающих гармоник в контактной сети постоянного тока. Библ. 9, рис. 5.

Ключевые слова: фактор пульсаций, мешающая гармоника, система автоматического регулирования, двухсторонняя широтно-импульсная модуляция, полупроводниковый преобразователь.

Problem definition. The main disadvantages of semiconductor converters with increased pulsation are:

- impossibility to create a converter with absolutely symmetrical shoulders, which leads to generation of harmonics, reduction of the quality of electric energy at the output of the traction substation and deterioration of the electromagnetic compatibility of the rectifier with the traction network. The problems of symmetrization of semiconductor converters remain unsolved in $[1,2]$;

- constant presence of non-canonical harmonics in output voltage, to which signaling, centralization and blocking (SCB) devices are critical and which do not depend on rectifier pulsation, due to the practical impossibility of creating an integer ratio of turns of high power transformer windings supplying rectifier bridges. At the same time, in $[3,4]$, the possibility of applying active filtering of harmonics of the output voltage of a semiconductor converter is not considered.

In addition, the cause of the disturbing harmonics is the discrete nature of the rectification conversion of the electric energy of the alternating current and the effect of the inherent asymmetry of the rectifier and the asymmetry of the supply network. These reasons cause the generation into the contact network of canonical and non-canonical harmonics. A large contribution to the formation of an interfering voltage is made by harmonics whose frequencies lie in the range $f_{m}=100 \ldots 1200 \mathrm{~Hz}$. The use to reduce the amount of interfering harmonics in the specified range in the composition of the smoothing filter of rejection $L C$ circuits is not effective enough $[5,6]$. This is explained by the difficulty of obtaining precise tuning of the rejection circuits at the frequencies of the interfering harmonics and changing the resonant frequencies caused by the temperature and time effects.

That is, it is actual to search for alternative technical solutions for combating the interfering harmonics of a semiconductor converter.

In [7] the questions of application of special closed structures for regulating the harmonics of the output voltage of the controlled converter were considered. However, the proposed systems with single-sided PWM

(C) V.V. Panchenko, A.S. Maslii, D.P. Pomazan, S.G. Buriakovskyi 
have a narrow bandwidth and do not allow high PWM frequencies to be realized.

Thus, in the context of the problem under consideration, the issues of using a semiconductor converter with a two-way PWM, as part of a closed automatic control system, remain unresolved to reduce the values of interfering harmonics and improve electromagnetic compatibility with the traction network.

The goal of the work is investigation of electromagnetic processes in the automatic control system of interfering harmonics of a semiconductor converter with a two-way PWM and obtaining expressions for determining the factors of pulsations acting in this system.

Main part. In the automatic control system containing a converter with two-way pulse width modulation (Fig. 1), two pulsation factors act [9].

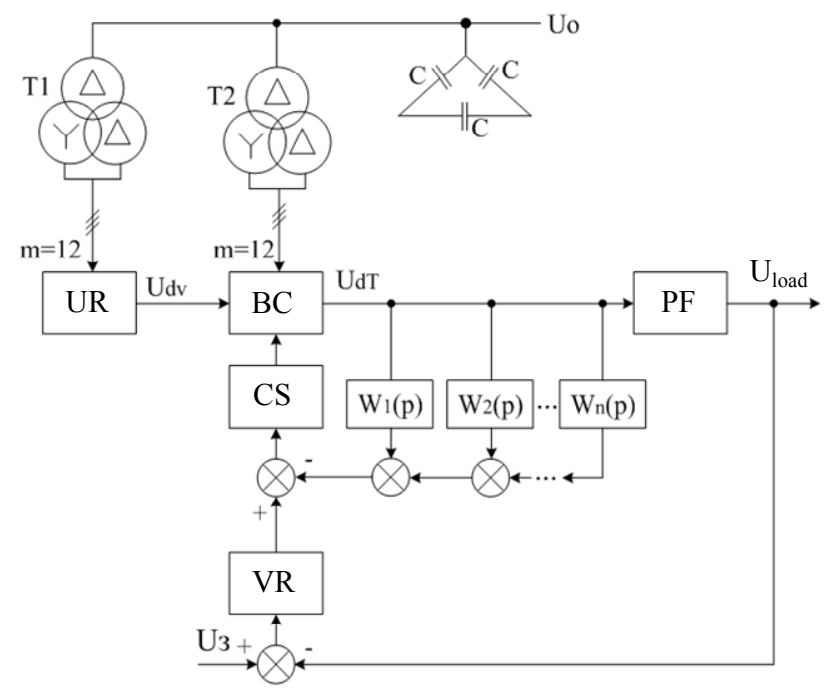

Fig. 1. Closed automatic control system of the semiconductor converter with two-way PWM

In the automatic control system under consideration, the main power flow from the mains to the load is transmitted through the main 12-pulse uncontrolled rectifier (UR). The wide-adjustable booster converter (BC) controlled by the control system (CS) is designed to transmit power, which is about $20 \%$ of the power of the main rectifier.

Stabilization of the voltage of the rectifier unit is ensured by negative feedback on the load voltage $U_{\text {load }}$ with the help of the voltage regulator (VR), and the regulation of the interfering harmonics of load voltage over a wide frequency range is performed by internal circuits containing selective links $\mathrm{W}_{1}(\mathrm{p}), \mathrm{W}_{2}(\mathrm{p}) \ldots \mathrm{W}_{\mathrm{n}}(\mathrm{p})$ with transfer functions.

The proposed automatic control system of the rectifier with a pulse-width-adjustable $\mathrm{BC}$ meets the requirements of astaticism. This requirement is achieved by the introduction of an integral part in the VR, as well as the use of adaptive feedback on the circuit suppression factor of the load voltage harmonics.

The main task of the L-shaped passive the $L C$-filter $(\mathrm{PF})$ in this system is the suppression of the harmonic of the voltage of the $\mathrm{BC}$ carrier frequency.
The use of a two-sided PWM instead of a onesided PWM is due to the possibility of extending the converter bandwidth, which will suppress the harmonics of the output voltage of a DC traction substation over a wide frequency range, and therefore reduce the volume of the $\mathrm{PF}$.

In the booster converter, the formation of a pulsewidth modulated pulse train is performed by a control system, the functional circuit of which is shown in Fig. 2. Functionally, the control system consists of a reference voltage generator RVG and a comparator $\mathrm{K}$.

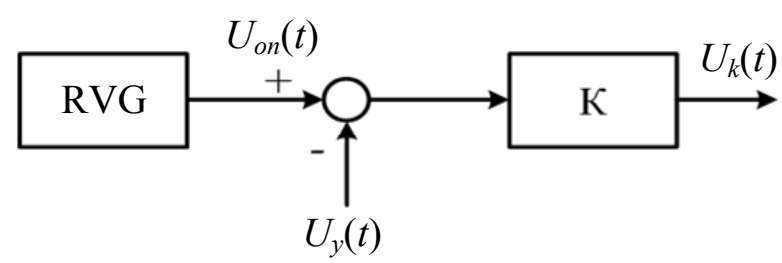

Fig. 2. Functional circuit of the control system

In [8] generalized expressions for the pulsation factors were obtained in the representation of the transfer function of the reduced continuous part as a sum of aperiodic links. For the system for suppressing the interfering harmonic, the expressions for the pulsation factors have the form

$$
\begin{gathered}
F_{1}^{-1}=1-\sum_{i=1}^{n} \frac{K_{P} T_{1}}{2 T_{i}} \cdot \frac{\left(1-e^{-\gamma \frac{T_{1}}{T_{i}}}\right) e^{-\frac{T_{1}}{T_{i}}}}{1-e^{-\frac{T_{1}}{T_{i}}},} \\
F_{2}^{-1}=1+\sum_{i=1}^{n} \frac{K_{P} T_{1}}{2 T_{i}} \cdot \frac{\left(1-e^{-\gamma \frac{T_{1}}{T_{i}}}\right) e^{-\frac{T_{1}}{T_{i}}}}{1-e^{-\frac{T_{1}}{T_{i}}}} .
\end{gathered}
$$

To apply formulas (1), (2), we represent the transfer function of the selective link $G(p)$ as a sum of aperiodic links

$$
G(p)=\frac{p}{T_{0}}\left(\frac{K_{1}}{p-p_{1}}+\frac{K_{2}}{p-p_{2}}\right),
$$

where $p_{1}=(-\xi+j a) / T_{0}, p_{2}=(-\xi-j a) / T_{0}$ are the poles of the transfer function $G(p)$.

The coefficients $K_{1}$ and $K_{2}$ are defined as the residues of the transfer function $G(p)$ in the corresponding poles

$$
\begin{gathered}
K_{1}=\left|\frac{p}{p-p_{2}}\right|_{p=p_{1}}=\frac{a+j \xi}{2 a}, \\
K_{2}=\left|\frac{p}{p-p_{2}}\right|_{p=p_{2}}=\frac{a-j \xi}{2 a} .
\end{gathered}
$$

Substituting (4) and (5) into (3) and transforming, we obtain

$$
G(p)=\frac{j}{2 a}\left[\frac{1}{T_{0}(\xi+j a)+1}-\frac{1}{T_{0}(\xi-j a)+1}\right]
$$

Taking into account (6), the expressions for the pulsation factors take the form 


$$
\begin{aligned}
& F_{1}^{-1}=1-j \frac{K_{p} T_{1}}{4 a T_{0}}\left\{\begin{array}{c}
(\xi-j a) \frac{\left[1-e^{-\gamma(\xi-j a)} \frac{T_{1}}{T_{0}}\right] e^{-(\xi-j a)} \frac{T_{1}}{T_{0}}}{1-e^{-(\xi-j a) \frac{T_{1}}{T_{0}}}} \\
-(\xi+j a) \frac{\left[1-e^{\left.-\gamma(\xi+j a) \frac{T_{1}}{T_{0}}\right]}\right] e^{-(\xi+j a) \frac{T_{1}}{T_{0}}}}{1-e^{-(\xi+j a) \frac{T_{1}}{T_{0}}}}
\end{array}\right\}, \\
& F_{2}^{-1}=1+j \frac{K_{p} T_{1}}{4 a T_{0}}\left\{\begin{array}{c}
(\xi-j a) \frac{\left[1-e^{-\gamma(\xi-j a) \frac{T_{1}}{T_{0}}}\right] e^{-(\xi-j a) \frac{T_{1}}{T_{0}}}}{1-e^{-(\xi-j a) \frac{T_{1}}{T_{0}}}} \\
-(\xi+j a) \frac{\left[1-e^{-\gamma(\xi+j a) \frac{T_{1}}{T_{0}}}\right] e^{-(\xi+j a) \frac{T_{1}}{T_{0}}}}{1-e^{-(\xi+j a) \frac{T_{1}}{T_{0}}}}
\end{array}\right\}
\end{aligned}
$$

Performing simple but rather cumbersome transformations in (7) and (8), we obtain expressions for the pulsation factors of the closed system for suppressing the interfering harmonics

$$
F_{1}^{-1}=1+j \frac{K_{p} T_{1}}{2 a T_{0}}\left\{\begin{array}{l}
\frac{C_{1.1} \cdot e^{-\xi \frac{T_{1}}{T_{0}}}-C_{1.2} \cdot e^{-\xi(1-\gamma) \frac{T_{1}}{T_{0}}}-}{1-2 e^{-\xi \frac{T_{1}}{T_{0}}} \cos a \frac{T_{1}}{T_{0}}+e^{-2 \xi \frac{T_{1}}{T_{0}}}} \\
\frac{-C_{1.3} \cdot e^{-\xi(2-\gamma) \frac{T_{1}}{T_{0}}}+a \cdot e^{-2 \xi \frac{T_{1}}{T_{0}}}}{}
\end{array}\right\}
$$

where

$$
\begin{gathered}
C_{1.1}=\xi \sin a \frac{T_{1}}{T_{0}}-a \cos a \frac{T_{1}}{T_{0}} ; \\
C_{1.2}=\xi \sin a(1-\gamma) \frac{T_{1}}{T_{0}}-a \cos a(1-\gamma) \frac{T_{1}}{T_{0}} \\
C_{1.3}=\xi \sin a \gamma \frac{T_{1}}{T_{0}}-a \cos a \gamma \frac{T_{1}}{T_{0}} ; \\
F_{2}^{-1}=1-\frac{K_{p} T_{1}}{2 a T_{0}}\left\{\begin{array}{l}
\frac{C_{2.1} \cdot e^{-\xi \gamma \frac{T_{1}}{T_{0}}}-C_{2.2} \cdot e^{-\xi \frac{T_{1}}{T_{0}}}+}{1-2 e^{-\xi \frac{T_{1}}{T_{0}}} \cos a \frac{T_{1}}{T_{0}}+e^{-2 \xi \frac{T_{1}}{T_{0}}}} \\
+C_{2.3} \cdot e^{-\xi(1+\gamma) \frac{T_{1}}{T_{0}}}-a \cdot e^{-2 \xi \frac{T_{1}}{T_{0}}}
\end{array}\right\},
\end{gathered}
$$

where

$$
\begin{gathered}
C_{2.1}=\xi \sin a \gamma \frac{T_{1}}{T_{0}}-a \cos a \gamma \frac{T_{1}}{T_{0}} ; \\
C_{2.2}=\xi \sin a \gamma \frac{T_{1}}{T_{0}}-a \cos a \frac{T_{1}}{T_{0}} ; \\
C_{2.3}=\xi \sin a(1-\gamma) \frac{T_{1}}{T_{0}}+a \cos a(1-\gamma) \frac{T_{1}}{T_{0}} .
\end{gathered}
$$

Fig. 3, 4 show the results of calculating the pulsation factors for different values of the controlled parameter $\gamma$, the damping coefficient $\xi$, and the frequencies of the interfering harmonics.

From the obtained dependences it follows that in contrast to a system with one-sided pulse-width modulation in a system with two-way pulse-width modulation, the effect of self-compensation of the action of pulsation factors is observed. There is a weak dependence of the pulsation factors on the damping coefficient. This is explained by the fact that the frequencies influencing the values of the pulsation factors lie outside the pass band of the selective link.
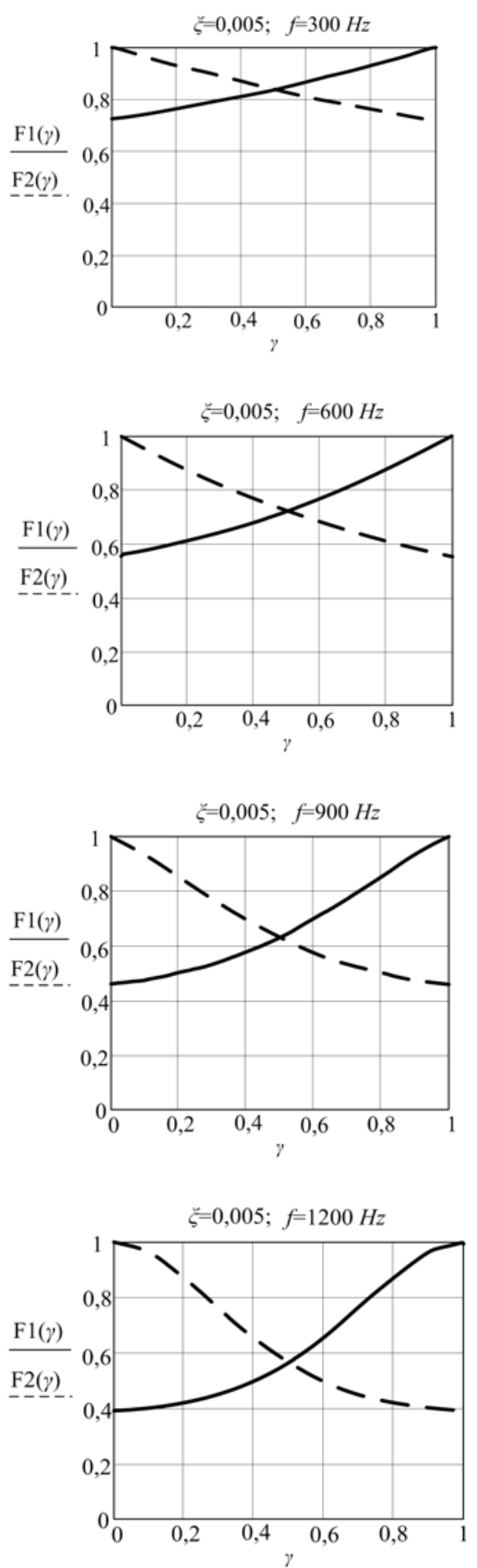

Fig. 3. The results of calculating the pulsation factors for different values of the frequency of the interfering harmonic $f$ 

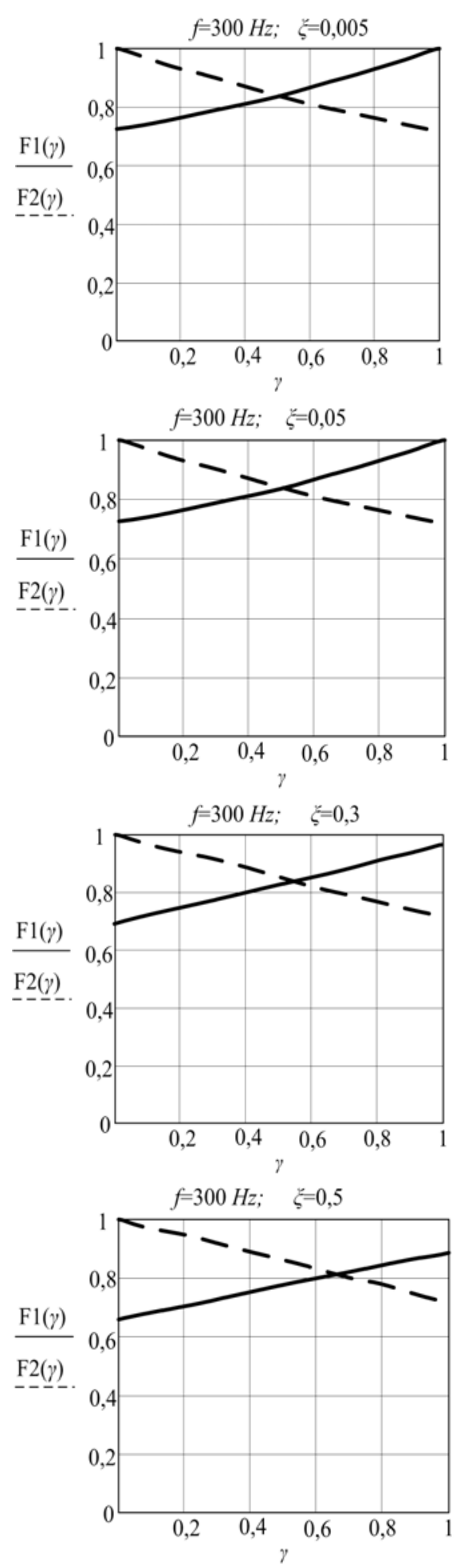

Fig. 4. The results of calculating the pulsation factors for different values of the damping coefficient $\xi$

The amplitude-frequency response of the selective link $G(p)$ in the region of higher frequencies has a slope of $-20 \mathrm{~dB} / \mathrm{dec}$. This gives a prerequisite for the approximation of the link $G(p)$ by an aperiodic link

$$
H(p)=\frac{1}{T_{e} p+1},
$$

having the same transmission factor as $G(p)$ at the pulsewidth modulation frequency.

The time constant of an aperiodic link is defined as

$$
T_{e}^{2}=\frac{1+\frac{f_{P W M}^{2}}{f_{q}^{2}}\left[\frac{f_{P W M}^{2}}{f_{q}^{2}}-2\left(1-2 \xi^{2}\right)-1\right]}{4 \pi^{2} \frac{f_{P W M}^{4}}{f_{q}^{2}}},
$$

where $f_{P W M}$ is the pulse-width modulation frequency; $f_{q}$ is the frequency of the $q$-th interfering harmonic.

In this case, the expressions for the pulsation factors take the form [6]:

$$
\begin{gathered}
F_{1}^{-1}=1-\frac{K_{p} T_{1}}{2 T_{e}} \cdot \frac{\left(1-e^{-\gamma \frac{T_{1}}{T_{e}}}\right) e^{-\frac{T_{1}}{T_{e}}}}{1-e^{-\frac{T_{1}}{T_{e}}}} ; \\
F_{2}^{-1}=1+\frac{K_{p} T_{1}}{2 T_{e}} \cdot \frac{e^{-\gamma \frac{T_{1}}{T_{e}}}-e^{-\frac{T_{1}}{T_{e}}}}{1-e^{-\frac{T_{1}}{T_{e}}}} .
\end{gathered}
$$

Fig. 5 shows the graphical dependencies characterizing the changes in the pulsation factor in the function of the regulated parameter $\gamma$, calculated from formulas (13) and (14).

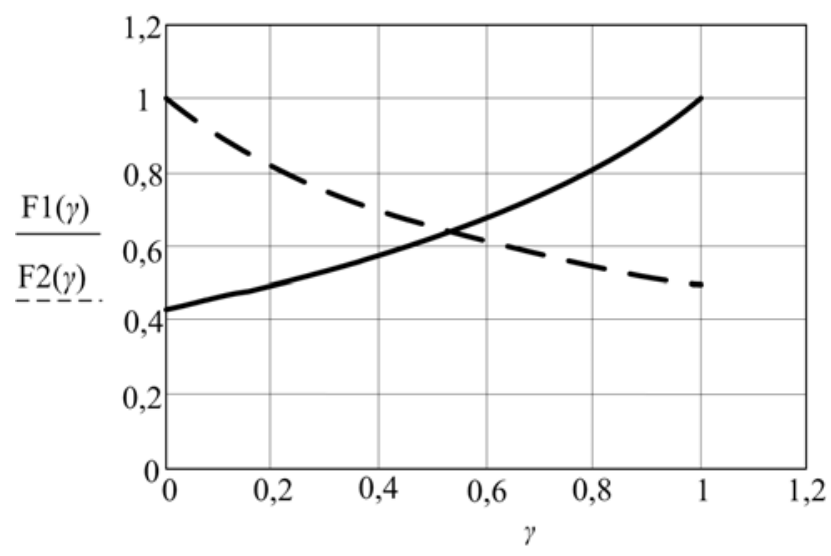

Fig. 5. Dependences of values of pulsation factors on $\gamma$

\section{Conclusions.}

For the first time, expressions were obtained for determining the pulsation factors of the automatic control system of interfering harmonics of a semiconductor converter with a two-way PWM for different values of the damping coefficient and the controlled parameter.

It is established that in the considered automatic control system of a semiconductor converter with twoway PWM, self-compensation of the action of pulsation factors occurs.

As a result of the investigation of electromagnetic processes in the automatic control system of a semiconductor converter, the possibility of suppressing interfering harmonics without interference in its power part was revealed. This is especially important in the maintenance of the rectifying installation of the traction substation.

\section{REFERENCES}

1. Richter J., Doppelbauer M. Control and mitigation of current harmonics in inverter-fed permanent magnet synchronous machines with non-linear magnetics. IET Power 
Electronics, 2016, vol.9, no.10, pp. 2019-2026. doi: 10.1049/iet-pel.2015.0977.

2. Ghanizadeh R., Ebadian M., Gharehpetian G.B. Non-linear load sharing and voltage harmonics compensation in islanded microgrids with converter interfaced units. International Transactions on Electrical Energy Systems, 2016, vol.27, no.1, p. e2237. doi: 10.1002/etep.2237.

3. Panchenko V.V. The harmonic composition of the output voltage of a rectifier unit with a PWM voltage booster converter. Information and control systems at railway transport, 2015, no.4, pp. 71-78. (Rus).

4. Kuznetsov B.I., Nikitina T.B., Tatarchenko M.O., Khomenko V.V. Multicriterion anisotropic regulators synthesis by multimass electromechanical systems. Technical electrodynamics, 2014, no.4, pp. 105-107. (Rus).

5. Sozański K. Three phase active power filter with selective harmonics elimination. Archives of Electrical Engineering, 2016, vol.65, no.1, pp. 33-44. doi: 10.1515/aee-2016-0003.

6. Huang J., Shi H. Suppression of the Peak Harmonics from Loads by Using a Variable Capacitance Filter in Low-Voltage DC/DC Converters. IEEE Transactions on Electromagnetic Compatibility, 2016, vol.58, no.4, pp. 1217-1227. doi: 10.1109/temc.2016.2552230.

7. Coillot C., Nativel E., Zanca M., Goze-Bac C. The magnetic field homogeneity of coils by means of the space harmonics suppression of the current density distribution. Journal of Sensors and Sensor Systems, 2016, vol.5, no.2, pp. 401-408. doi: $10.5194 /$ jsss-5-401-2016.

How to cite this article:

Panchenko V.V., Maslii A.S., Pomazan D.P., Buriakovskyi S.G. Determination of pulsation factors of the system of suppression of interfering harmonics of a semiconductor converter. Electrical engineering \& electromechanics, 2018, no.4, pp. 24-28. doi: 10.20998/2074-272X.2018.4.04.
8. Scherbak Y.V., Ivakina K.Y., Panchenko V.V. Factor pulsations automatic regulation with two-way pulse width modulation. Collected scientific works of Ukrainian State University of Railway Transport, 2015, no.153, pp. 113-120. (Rus). doi: 10.18664/1994-7852.153.2015.64336.

9. Panchenko V.V. Dynamic properties of system «rectifier with buck converter - load». Eastern-European Journal of Enterprise Technologies, 2013, vol.4, no.8(64), pp. 14-17. (Ukr).

Received 12.04.2018

V.V. Panchenko ${ }^{1}$, Candidate of Technical Science, Associate Professor,

A.S. Maslii ${ }^{1}$, Candidate of Technical Science, Associate

Professor

D.P. Pomazan ${ }^{1}$, Postgraduate Student,

S.G. Buriakovskyi $i^{2}$ Doctor of Technical Science,

${ }^{1}$ Ukrainian State University of Railway Transport,

7, Feierbakh Square, Kharkiv, 61050, Ukraine,

e-mail:vlad_panchenko@ukr.net, a.masliy@ukr.net, danil.pomazan@ukr.net

${ }^{2}$ Scientific-\&-Research Planning-\&-Design Institute

National Technical University «Kharkiv Polytechnic Institute», 2, Kyrpychova Str., Kharkiv, 61002, Ukraine,

e-mail: sergbyr@i.ua «Molniya», 